\title{
ECONOMIC ISSUES IN VACCINE \\ PURCHASE ARRANGEMENTS
}

David S. Salkever

Richard G. Frank

Working Paper 5248

\author{
NATIONAL BUREAU OF ECONOMIC RESEARCH \\ 1050 Massachusetts Avenue \\ Cambridge, MA 02138 \\ September 1995
}

Prepared for the National Vaccine Program Office, U.S. Department of Health and Human Services. This paper is part of NBER's research programs in Health Care and Health Economics. Any opinions expressed are those of the authors and not those of the National Bureau of Economic Research.

(c) 1995 by David S. Salkever and Richard G. Frank. All rights reserved. Short sections of text, not to exceed two paragraphs, may be quoted without explicit permission provided that full credit, including $\odot$ notice, is given to the source. 


\title{
ECONOMIC ISSUES IN VACCINE \\ PURCHASE ARRANGEMENTS
}

\begin{abstract}
Federal purchases of major childhood vaccines account for roughly half of the total market for these vaccines. This paper examines Federal purchasing practices in the context of the recent literature on bidding and procurement, and compares these practices to UNICEF vaccine procurement arrangements. Federal contracts were awarded to a single winner and the firms eligible to bid were limited in number (since the number of U.S. licensed firms is small). Since production capacity cannot be expanded quickly, and the Federal share of purchases is large, it is hypothesized that firms' bid prices will be higher for larger contracts. The paper analyzes contracts over the period 1977 through 1992 to determine the contract size-price relationship, as well as effects on contract prices of 1) the National Vaccine Injury Compensation Program enacted in 1987 and 2) changes in numbers of firms in the market. Results provide equivocal support for a positive size-price relationship and evidence of a positive price effect of the injury compensation program.
\end{abstract}

David S. Salkever

Department of Health Policy and Management Johns Hopkins School of Public Health 624 North Broadway Baltimore, MD 21205 and NBER
Richard G. Frank

Department of Health Care Policy Harvard Medical School

25 Shattuck Street

Boston, MA 02115 and NBER 


\section{The Economica of Purchesing Policy}

\section{A. Objectives of Purchasing Policy}

Economic analyses of government purchasing arrangements have been undertaken for a variety of industries over the past decades. A principal motivation in these analyses is to understand how purchasing arrangements affect the price taxpayers pay for the purchased good or service. Obtaining the service at

a lower price is generally viewed as desirable, if only on purely distributional grounds. In other words, a purchasing arrangement that yields a lower price to the government is viewed as desirable because it transfers income from the producer (who is presumably earning profits above the perfectly competitive level) to the public in the form of reduced taxes. This result may also be viewed as promoting efficiency of resource allocation if a lower price results in a greater quantity of the good or service provided and if the price paid measures the incremental value in consumption of this good or service. The literature has also examined a related efficiency issue in purchasing, namely, the conditions under which the lowest-cost producer actually wins the contract.

Uncertainty and limited information available to government purchasers introduce new objectives into the purchasing process. one such objective is to insure against supply disruptions. A second is to generate information through the purchasing process that will be useful to the government either in subsequent procurements or in monitoring contract performance. 


\section{B. The Elements of Purchasing Policy}

Purchase of goods or services under government contracts can be viewed as a two-stage process. In stage one, bids are requested, received and evaluated and one or more procurement contracts are negotiated. In stage two, the contracts are carried out and the purchased goods or services are delivered. Several different features of this process may influence the final result in terms of the cost, quantity and quality characteristics of the goods or services actually received.

First, the government purchaser must select between competitive and sole source (or preselected) procurements. The former offers the advantage of potentially lower contract prices but involves greater costs in the procurement process itself (e.g., costs for preparation of bids by a number of potential suppliers and review of those bids by the government). In a world of complete information, the government purchaser with monopsony power could select the firms it wishes to contract with in advance and then negotiate with each on a sole source basis. The assymetry of information between the government and seller makes competitive procurement more attractive as an option. By committing itself to a competitive procurement process, with the rules for selecting the competitors defined in advance, the government can induce bidding behavior which may result in a more favorable outcome than is attainable through bargaining with pre-selected firms. Moreover, the competitive process greatly reduces the possibility of no agreement being reached when a 
mutually beneficial exchange is in fact possible. This is because, in a bargaining situation, considerations of bargaining strategy, power and "brinkmanship" can result in failure to reach mutually beneficial agreements (Milgrom 1989).

Second, in the case of competitive procurements, the government must set the rules for conducting the bidding, selecting the winning bidder(s) and determining the contract price(s). A bewildering variety of bidding processes have been examined theoretically and many are observed in the private sector that the government could choose from. Auctions may be open or closed (i.e., sealed-bid). Prices may be set at the lowest bid price, the second-lowest bid price, an average price for selected bids, and so on. Different prices may be used in contracts with different bidders (i.e., discriminatory instead of uniform-price auctions). Reservation prices' may be set and announced, and bidders may be required to pay a participation fee for submitting a bid. Different bidders may be treated differently in the bidding process; for example, some bidders may be charged higher participation fees than other bidders, or preferences may be given to domestic over foreign firms in the selection process. Finally, the government may determine in advance the number of contracts to be awarded. Conflicting tendencies may be noted in this regard. Efficiency may dictate

${ }^{1}$ Reservation prices are minimum or maximum prices. A reservation price for a procurement contract would be the maximum price the government is willing to pay rather than forego the procurement entirely. 
selecting the single lowest cost bidder; concerns about possible supply disruption may argue for selecting several bidders.

Third, the government purchaser must specify features of the contract in advance. One very important feature is whether to use a fixed price versus a profit-sharing or incentive contract. In the latter case, the actual price paid by the government may be above (below) the contract price because, for example, of contractors' cost overruns (underruns); if the entire amount of the cost discrepancy is paid by the government, the contract is simply a cost-reimbursement agreement. A second important contract feature is the quantity to be purchased. This may be specified in advance or it may be left unspecified. In the latter case, upper and/or lower limits on quantity could be specified even though the precise quantity is not. Note that when there are multiple suppliers, the government may also specify the total purchase quantity but allow the division of that total among the suppliers to depend upon the levels of their respective bids.

It is also possibile to combine the competitive and pre-selected procurement processes. The government may limit competition to pre-selected bidders who meet particular criteria. For example, only firms licensed to produce a particular vaccine could be allowed to bid on a procurement contract for that vaccine (as is done in the U.S.). In addition, the negotiation aspect of the pre-selected procurement process could also be used in the final stage of a competitive procurement. Final 
agreements on price and other contract terms could be negotiated between the government and the competitively selected suppliers before the contracts are awarded.

In the second stage of the process, the execution of the contracts, the government purchaser may engage in monitoring of quality and (in the case of incentive contracts) verification of supplier costs and profits. The government may also determine during this phase the exact quantities of the good or service it desires to purchase (if these have not already been predetermined). It will generally be advantageous to the government to specify in advance (i.e., before bids are prepared) the methods used for monitoring and the process used for determining quantities to be purchased.

\section{c. The Influence of the Procurement Process on outcomes}

Theoretical analyses of alternative competitive procurement (or bidding) methods have yielded a variety of conclusions about desirable and undesirable features of different approaches. These conclusions have of necessity been based on stringent assumptions and simplifications. While these assumptions and simplifications qualify the applicability of theoretical findings, several conclusions that may be generalizable have emerged.

$$
\text { Sealed vs. Open Bids }
$$

The use of sealed-bid auctions is common in procurement 
contracts. ${ }^{2}$ since it seems reasonable to assume that bidders' valuations of each contract are not independent of one another, ${ }^{3}$ auction theory suggests that government purchasers may pay a higher price with sealed bids than with open bids (Riley 1989). Other factors may explain the widespread use of the sealed bid approach, however, including bidders' risk aversion (Riley 1989) and the greater possibilities of bidders' collusion in open auction procurements (Milgrom 1989).4 When the quantity to be supplied is not predetermined and is dependent on the contract price, the preference for the sealed-bid auction is reinforced. In this endogenous quantity case, the sealed-bid auction leads to a lower price and a greater expected level of profit for the

2 Sealed-bid auctions refer here to sealed-bid, first-price auctions while open bids refers to the English open outcry auction. The sealed-bid first-price auction and the open auction are theoretically identical to the Dutch auction and the sealed-bid second-price auction respectively. Thus the literature generaliy does not deal specifically with the latter two procurement forms.

3 In the auction theory literature this is referred to as the case of affiliated values.

4 The second-price sealed-bid auction also reduces the risk of collusion and may offer lower expected prices to the government; Milgrom (1989) suggests that it may be infrequently used because it is susceptible to manipulation by inserting a false bid and thus setting the contract price to that of the lowest-priced real bid. The reader should also note that sealed-bid processes are certainly not immune to collusion. Cases and allegations of bid-rigging in many procurement markets (e.g., milk, Treasury bonds, construction contracts) have been frequent. 
bidders (Hansen 1988, Milgrom 1989).

\section{Prices and Contract Terms}

The usual theoretical qualifications aside, recent reviews of the auction literature suggest that uniform prices (where all winning bidders pay the same price) are preferable to price discrimination among winning bidders (MCAfee and McMillan 1987; Milgrom 1989; Bikhchandani and Huang 1993). Empirical evidence from government bond markets in the U.S. and, more recently, in Mexico support this preference. 5

There is also general agreement that incentive provisions in a contract will tend to produce results from the bidding process that are more advantageous to the government. McAfee and McMillan (1986) demonstrate that incentive (1.e., profit-sharing) contracts are advantageous to the government both because of a "bidding competition effect" and because of risk-sharing (in the case where bidders are risk averse)..$^{6}$ While the optimal profit-sharing rate exceeds zero, it is also less than one (the cost-reimbursement case) because contractors devote less effort to keeping contract costs low when profits are shared with the government. This "moral hazard" problem arises because the levels of contractors' efforts to control costs are not directly

5 A contrary view of the empirical literature - that uniform vs. discriminatory pricing does not affect contract price - has been expressed by seshadri et al. (1991).

6 The preference for incentive contracts is also an example of the "linkage principle" (Milgrom 1989). 
observable. This point brings up one other disadvantage of the incentive contract approach, namely, the need for the government to observe the costs and profits of the contractor. The administrative burden of cost-reporting and auditing may not be negligible.

Selecting Contractors and Allocating Quantities

We previously noted that certain classes of bidders may be accorded preferential treatment in the selection of winning contractors. Theoretical analysis (McAfee and McMillan 1987) suggests that preferential treatment should be given to higher cost suppliers; an explanation for this result is that preference for higher cost suppliers induces lower cost suppliers to submit lower bid prices than they would in the absence of this preference. A specific application of this is sequential procurement involving development and "follow-on" contracts. Luton and MCAfee (1986) argue that when the developer has a cost advantage, preference in follow-on procurements should be given to other firms.

Should the government select a single contractor or should it award several contracts? If the latter, how should the purchased quantity be divided up among the winning contractors? The multiple-source decision depends upon several factors (Seshadri et al., 1991). Post-award control of contractors' costs is thought to be more effective with multiple contractors. Multiple sourcing also provides some protection against supply disruptions. Given the number of potential bidders, multiple 
sourcing may also increase the number of bids and lead to lower contract prices, but the opposite effect is also possible and even perhaps more likely in the presence of economies of scale (Seshadri et al. 1991). A recent empirical study of aerospace defense contracting reports that multiple-source awards result in higher contract prices to the government (Greer and Liao 1986).

In the case where contracts have been awarded to multiple sources, the literature unfortunately tells us little about alternative methods of allocating the quantity purchased among the winning bidders. Seshadri et al. (1991) speculate that equal allocation may be preferable and that allowing winning bidders to compete with one another after being selected may be a useful means of contractor performance control. On the other hand, specifying the allcations a priori may reduce uncertainty and encourage more firms to bid (a la McAfee and McMillan's "bidding competition effect").

\section{Other Factors Influencing procurement outcomes}

The empirical literature on bidding prices is sparse but several relevant and intuitive conclusions have emerged thus far. Competition, in the form of greater numbers of potential bidders, greater numbers of actual bidders, or the absence of collusion, leads to lower contract prices (McAfee and McMillan 1987).

Greer and Liao (1986) find that the level of capacity utilization is also positively related to contract prices. They speculate that this effect arises because 1) aerospace production requires a substantial capital investment and 2) the opportunity 
costs of foregone private sector business (due to capacity limits) increase when plant utilization rates are high. The implicit assumption is that private sector business is more profitable. In a long run equilibrium with free entry and competitive pricing, private sector profits would not exceed the perfectly competitive level. Thus, Greer and Liao's interpretation also implies persistent market power and supracompetitive profits in the private market. 
II. Vaceine Purchese Policy in the onited states and by ovICEF

The Centers for Disease Control and Prevention (CDC) is charged with procurement of a number of different vaccines under the Vaccine Shared Procurement Program. All vaccine procurement is governed by the the general contracting rules set forth in the Federal Aquisitions Regulations (FAR). Those regulations promote competitve bidding for government contracts. The contracts negotiated and awarded by CDC define the conditions of purchase, including prices, for various federal agencies and certain approved state and local health agencies. Approximately, 458 to 55t of childhood vaccines are purchased under the CDC contracts (Institute of Medicine, 1993 and CDC).

The CDC solicits bids from all licensed manufacturers of a particular vaccine usually on a yearly basis. A request for proposals is sent to licensees and an announcement of the solicitation is published. Requests for proposals for one of two types of contracts are distributed: requirements contract and indefinite quantity contracts. The requirements contract does not specify a minimum or maximum purchase quantity but potential bidders are provided with an expected purchase quantity. The indefinite quantity contract specifies a minimum and maximum as well as an expected purchase quantity. The vast majority of contracts are indefinite quantity contracts.

Table 1 reports the number of licenses for the DPT, MMR and OPV vaccines for the years 1977 to 1992. The Table illustrates a 
substantial reduction in potential competitors over the past 15 years. Both the OPV and MMR vaccines are available from only one licensed producer in the U.S. A number of reasons have been offered as to why reductions in potential competition have taken place (Institute of Medicine 1993). Liability risks, FDA regulation and the relative profitability of other lines of business have all been identified as factors influencing the reduction in competition (Institute of Medicine 1993, National Vaccine Advisory Committee Hearings February, 1993).

Table 2 reports the number of bidders on specific childhood vaccine contracts during the period 1985-1992. It is clear from this table that actual competition is more limited than indicated by the number of active licenses; in no case does the number of bidders exceed two except for TD vaccine. The reasons for this may be similar to those contributing to a decrease in licenses. In particular, if production facilities are being allocated to other, more profitable, product lines then the effective stock of potential bidders would be less than that implied by the number of licenses. This may indicate a potential for capacity constraints on the supply of an individual vaccine in any particular year.

Contracts are awarded by $C D C$ to the lowest bidder in a winner take all competition. It should be noted that in a few infrequent cases multiple contracts are awarded usually because there is clear evidence that a single bidder will not be able to produce sufficient quantity to meet the expected purchase level. 
In the common case where there is only one bidder and the amount to be purchased exceeds $\$ 100,000$, the FAR requires cost information to be submitted with the bid. Bidders are permitted to request an exemption from providing cost data if they can provide catalogue price data. This information then forms the basis for price negotiations between CDC and manaufacturers.

Recent congressional action (P.I. 101-66) modified the federal purchasing arrangements in several respects. First, for vaccines purchased under contract as of May 1993, increases in future contract prices are limited to the economy-wide rate of price inflation. Since contract prices have in fac $t$ been going down in real terms in last four or five years (see Table 3), it is unclear if this price constraint will be binding. Second, vaccine companies are now required to supply states with their desired quantities of vaccines at the federal contract price. since the size of state purchasesx are not specified in advance, this increases the effective size of the federal contract by an uncertain amount.

UNICEF which is the largest purchaser of vaccines in the world uses a rather different set of procedures to govern its procurement process. ${ }^{7}$ Every two years UNICEF solicits bids from companies that have met World Health organization (WHO) standards for vaccine production. Companies must pay for wHO to evaluate their manufacturing capabilities and their nation's drug

7 UNICEF purchased about 850 million doses which cost $\$ 65$ million dollars in 1992 . 
regulatory apparatus. The companies receiving who approval then submit competitive bids to supply vaccine. Unlike the CDC procurement process the competition is not a winner take all contest. This is in part due to the large quantities being bought which makes a winner take all auction impractical. Another reason is to encourage an expansion in the number of suppliers of vaccines.

The lowest price bidder gets the largest purchase order (up to two thirds of the total amount to be procured by UNICEF). Bidders making higher offers are then asked to resubmit bids. Since most firms cannot supply two thirds of the UNICEF quantity, they supply their capacity and the remainder of the order is met by other firms in inverse relation to their bid price (lower bids get larger orders).$^{8}$ The results of this process are exemplified by the fact that there are 5 firms which bid and supply DPT vaccine and 4 firms bid and supply polio vaccine. The total number of firms bidding on childhood vaccines expanded during the 1980s. (European firms account for $90 \%$ of supply.) In addition prices paid per dose by UNICEF tend to be far lower than those paid by CDC (e.g. $\$ 0.08$ vs $\$ 6.25$ for DPT in 1992).

III. An Empirical Analysis of Vaceine Pricing

In order to begin to assess several key aspects of vaccine procurement in the United states we conducted an exploratory

8 This description is based on the description given in Institute of Medicine (1993) and from conversations with officials at CDC and UNICEF. 
empirical analysis of vaccine pricing. In this analysis we focus on the markup (or mark down) of CDC vaccine prices relative to private market prices as measured by catalogue prices. The analysis examined four main issues. First, we described price behavior of several major childhood vaccines. Second, we examined the relationship between the expected volume of sales and the bid price. This analysis potentially offers insight into the presence of capacity constraints and the opportunity-cost, differential profitability argument presented by Greer and Liao (1986). The presence of decreasing short-run average costs suggests a negative relationship between volume and bid price. Capacity constraints and opportunity cost considerations would suggest a positive association between expected volume of sales and the bid price. The third issue studied is the relationship between the number of potential competitors (licensees) and the purchase price. Fourth, we explore the relation between the number of bidders and the purchase price of a vaccine. (Our ability to address both of these issues is limited, however, by the small variation in numbers of licensees and bidders.) In addition, we also consider possible discontinuity in price behavior with the enactment of the liability compensation program.

In order to examine these issues we constructed two data sets. The first data set consists of data for three vaccines for the years 1977 through 1992: DPT, MMR and OPV. We were able to obtain data on the CDC purchase price, the catalogue price, the number of producers licensed in each year and the expected number 
of doses to be purchased. The price and expected number of doses data were provided to us by the $\operatorname{CDC}^{9}$ The data on licensing was obtained from the recent Institute of Medicine (1993) report which reports the licensing histories for major vaccines. The second data set consisted of information on 5 vaccines for the years 1985 through 1992: DPT, MR, OPV, HIB and DT. That data set included information on CDC purchase price, catalogue price, the number of firms bidding on the contract, the expected number of doses to be purchased, and the number of firms licensed. The second data set has the advantage of including information on the number of bidders and a larger number of vaccines. These data were made available to us by the CDC. The information on catalogue prices is incomplete as is the expected number of doses to be bought. Finally, there was virtually no variation in the number of bidders within vaccine type over time.

\section{A. Price Behavior}

Table 3 presents time series real price data for government contracts for DPT, MMR and OPV. Vaccine prices have grown at rates well above the growth in the general price level for the period 1977 to 1992. The DPT price in 1992 was nearly 18 times the 1977 level. The real price of MMR in 1992 was 2.74 times the 1977 price and the OPV price in 1992 was almost 3 times what it was in 1977 . In recent years (since 1988) the real prices of MMR and DPT have actually fallen. The price of OPV has not shown much

9 We are grateful to Rex Ellington for providing us with these data and for his help in understanding them. 
of a secular increase since 1986, when its price nearly doubled. Thus, most of the dramatic price increases for vaccines occurred in the early to mid-1980s.

Figure 1 shows the movement in the ratio of the government purchase price to the catalogue price for the DPT, MMR and OPV vaccines. The DPT vaccine shows a great deal of fluctuation in the ratio since 1977 . Yet the price ratio in 1992 was 0.7 compared to a value of 0.8 in 1977 . The price ratios for MMR and OPV display considerably more stability. The MrR ratio of government to catalogue price rose steadily from a value of 0.4 in 1977 to 0.6 in 1992. Thus the real CDC purchase price for Mar was 608 of the catalogue price in 1992. OPV's ratio fell slightly from 0.3 in 1977 to about 0.23 in 1992. The conclusion is that the CDC purchase price tracked the market price relatively closely albeit at a lower level.

B. Multivariate Analysis of Prices

We estimated a set of multiple regression models to investigate the influence on vaccine procurement price of the expected number of doses to be sold and the number of actual and potential competitiors. Table 4 defines the specific variables used in the analyses. We focus primarily on the 1977 through 1992 data set because the number of observations are largers, the data set is more complete (less missing data) and because we are able to estimate so-called fixed effects models. ${ }^{10}$ In the analysis

10 The fixed effects estimator produces consistent but inefficient estimates of the model's parameters. For a recent discussion of such models see Judge et al. (1991). 
reported here we estimate a seperate intercept (or fixed effect) for each of the vaccines included in the data set (DPT, MMR and OPV). This allows us to account for unobserved time invariant differences in the production and market conditions for each vaccine.

The dependent variable in all models estimated is the logarithm of the CDC purchase price. The independent variables vary slightly under different model specifications. There is some missing data for the expected number of doses to be purchased. This is due to a change in the mechanism through which DPT was bought during the 1980s. Thus the logarithm of the expected number of doses is not used in all models estimated. The number of active licenses to produce a vaccine is specified in linear form. We also include a dichotomous dummy variable that takes on a value of 1 beginning in 1988 and is equal to zero in previous periods. This variable is included to account for the implementation of the National Vaccine Injury Compensation Program. The implementation of this program was accompanied by imposition of an excise tax that would fund the program. We included a linear time trend in some specifications to account for unobserved secular trends. Finally, we included dichotomous dummy variables for the DPT and MMR vaccines with the OPV vaccine serving as the reference category.

Table 5 reports the regression results for the data set comprised of the years 1977 through 1992 and the DPT, MAR and OPV 
vaccines. The results are generally consistent across specifications. All the models fit the data quite well as evidenced by the $R^{2}$ of 0.97 in all three models. The first column presents the most complete specification of our pricing models. Note that this causes us to lose 7 observations due to missing values in the expected doses variable. The coefficient estimate for the log of the catalogue price (LNCP) was 0.709 . This indicates that a 10 increase in the catalogue price results in a 7.17 increase in the CDC purchase price. The estimate is significant at the 0.01 level. For the other two specifications of our model we cannot reject the hypothesis that the coefficient (or the elasticity of CDC price to catalogue price) is equal to one indicating that CDC purchase price rises proportionally to the catalogue price.

The coefficient estimate for the number of active licenses, our measure of potential competition, is positive but not significant at conventional levels. The $t$ statistic for the estimate is 1.45 . This general finding is consistent across all three model specifications reported on Table 5. For the other specifications of the number of licenses (NLIC) variable the $t$ statistic for the coefficient estimate is never significant.

The estimated impact of the expected number of doses to be purchased by CDC is positive and significant $(p<0.01)$. The coefficient estimate of 0.218 implies that a 10 increase in the expected number of doses to be purchased results in a CDC purchase price that is $2.2 t$ higher. This result is consistent 
with the notion of capacity constraints in sales to the CDC. Declining short-run average costs do not appear to offset the influence of possible capacity constraints in the supply to CDC.

The estimated impact of the dummy variable representing initiation of the National Vaccine Injury Compensation Program indicates between a $30 \%$ and 33 increase in CDC purchase price following implementation of the program." This result means that the effect of the excise tax dominated any reduction in costs stemming from the insurance protection offered by the program. Finally, the coefficient for the time trend was estimated to be 0.026 which amounts to a 2.68 average yearly increase in the real price of the three vaccines.

The results based on estimating similar models for the data set comprised of the years 1985 through 1992 for the DPT, MMR, OPV, HIB and DT vaccines were disappointing because the results were very sensitive to small changes in model specification. In one model made up of 29 observations with the number of bidders, the log of expected doses to be purchased, the log of catalogue price and the dummy variable indicating the implementation of the National Vaccine Injury Compensation Program as explanatory variables the number of bidders was estimated, controary to expectations, to have a positive and significant effect on CDC purchase price $(p<0.01)$. The effect on expected purchase level was estimated to be negative and significant $(p<0.01)$, while the

11 The effect is calculated as $e^{b}-1$ where $b$ is the estimated coefficient of the dummy variable. 
catalogue price elasticity was estimated to be 1.47 . This coefficient seems implausibly large. In contrast when a model with a larger number of observations is estimated (37 observations) and we replace the number of bidders with the number of licensees and drop the catalogue price variable (because of missing data) we find that the coefficient for the log of expected number of doses to be purchased is positive and significant $(p<0.05)$. Moreover the estimated impact for the number of active licenses is negative though not significant at conventional levels. Furthermore, simply replacing the number of bidders with the number of licensees creates changes in the coefficient of the other variables in the smaller data set of $30 \%$ to 60\%. Further analysis of the 1985-1992 data set, with missing data items filled in, will probably be needed to obtain reliable results for the pricing models. Limited degrees of freedom and variabilitiy of key variables (such as the number of bidders) precludes us from reaching substantive conclusions on the basis of the current analysis.

The instability of the results from the 1985-1992 data set leads us to cautiously assess our findings. We believe our results point to several areas for further investigation. First, the issue of capacity constraints is potentially quite important. The results for the 1977-1992 data set point to the possibility that such constraints exert an influence on the CDC purchase price. Some of the results from the 1985-1992 data set also point in that direction. The possibility that capacity constraints may 
be binding has implications for the winner take all approach used by CDC. In some cases where multiple licensees exist altering those rules might cause a relaxation of the capacity constraint. As already noted, our findings regarding nubmers of bidders and/or potential bidders (licensees) are counterintuitive and unstable. They also appear to conflict with the experience of UNICEF. Further examination of the market dynamics and the effective level of competition in this market needs to take place.

Another possible explanation for our estimates regarding numbers of licensees is that the list catalog price responds in the same way to the number of firms in the market as does the government purchase price. Since we have controlled for the catalog price in our analyses, no additional effect of the number of suppliers is observed. Given the modest role of large purchasers in the private market for vaccines, one might expect to see different price responses to changing market structure in the private versus public sectors. This is not confirmed by our empirical results however. ${ }^{12}$

A second explanation for the absence of any significant negative relationships between competition (as measured by the number of bidders) or potential competition (as measured by the number of licensees) is the possibility of collusive behavior in

\footnotetext{
${ }^{12}$ The reader should also note that when the catalog price is dropped from our empirical models, the expected negative relationship between number of suppliers (or potential suppliers) and price is still not observed.
} 
the industry. The economic theory of auctions (discussed above) shows that some auction mechanisms generate lower costs for the buyer because they reduce the potential for collusion. For example, Robinson (1985) shows that for one time purchases a sealed-bid first-price auction will yield lower costs to the buyer than will, say, an oral auction. The reason for this is that in an oral auction a collusive equilibrium is incentive compatible whereas in the sealed-bid first-price auction a bidder has strong incentives to cheat on any collusive agreement thereby making collusion incentive incompatable. The one time purchase environment does not correspond closely to the conditions within which CDC procurements occur. Instead, the CDC Vaccine procurement environment might be viewed as a repeated game among a small and relatively stable group of players whose size is defined in great measure by FDA licensing rules.

The theoretical research on collusion in the context of repeated games shows cartels (collusive agreements) can and do form even when auctions are run as first-price sealed-bid auctions (Robinson 1985, Friedman 1971). Thus, the conditions for bidding set by $\mathrm{CDC}$ and other branches of the federal government are quite conducive to collusion. Burnett and Kovacic (1989) describe collusive agreements that arose in response to the use of similar procurement techniques in the U.S. Defense Department's weapons aquisition process. (Note that a collusive result can occur without formal agreements to collude; in a repeated game situation, regular patterns of behavior can evolve 
informally.)

We believe much can be learned by conducting an assessment of pricing in the international vaccine market. A careful analysis of the UNICEF procurement experience as well as procurement policy by other countries would be relevant for reconsidering the specific aspects of the approach taken in the U.S. by the CDC. UNICEF procurement rules are in many respects more consistent with the enhancement and longrun development of competitve forces in the market for vaccines than those used by the CDC in this country. Specifically, UNICEFs relatively flexible rules regarding which firms may bid on vaccine contracts appears to eapnd the number of potential bidders with very little threat to the quality of vaccines purchased. The awarding of multiple contracts also offers advantages both in terms of reducing risks of supply interruptions and for maintaining the presence of firms capable of bidding for contracts in the future.

In general the procurement practices of UNICEF more closely resemble practice used in private industry procurement programs than do the practices of CDC. Private industry typically diversifies among suppliers especially in situations where supply interruptions are very costsly. Supply interruptions in vaccines are quite costly in both economic and political terms. The use of multiple suppliers also allows for longer duration contracts since it reduces the potential that firms winning contracts will engage in opportunistic behavior that might result in costly renegotiation of contracts. Longer term contracts may allow for 
lower administrative costs and more predictable expenditures for the government.

IV. Other Criticiens of the Government Purchase Model

Other possible concerns about the role of the government as a large purchaser in the market for vaccines have been expressed or implied. One such concern is that short-run exploitation of monopsony power by the government will lead to suboptimal outcomes such as subcompetitive profits in the short run, suboptimal investment in research, and/or slower introduction of new products in the long run. (The connection between international differences in price levels and international differences in diffusion of new products has been noted in the market for pharmaceuticals; see Johnston, 1990.) There is also the possibility that the government monopsonist will have a different valuation of an incremental purchase than will the consuming public; thus, the government monopsonist, concerned with the inframarginal price increases of additional purchases of vaccine, may purchase suboptimal quantities of vaccines. (For an analogous argument in the case of health insurance, see Pauly, 1988.)

Finally, it could also be argued that the government as a very large purchaser may feel free to act in a capricious manner in the procurement process. The theory of auctions suggests, however, that this behavior would be counter-productive. Paradoxical as it may sound, it is only by committing itself in advance to well-defined procurement procedures and following 
those procedures that the government can exploit its market power in the procurement process (Milgrom, 1989). Moreover, there is now a substantial history of government procurement activities in the U.S. This history does not illustrate, to our knowledge, frequent instances of "abuse" of government power, favoritism, or capricious behavior. There is little evidence to suggest that the Federal vaccine procurement process has been more subject to these problems than would be the case for private-sector procurements. On the other hand, since the government role in this market is so large and the consequences of abuse of power are potentially quite serious to the vaccine industry and to the country, this concern can not be taken lightly.

\section{Extending the 8cope of Foderal Purchasing}

Various policy proposals have been made to expand the scope of Federal purchasing. One example is to make the Federal government the sole purchaser of vaccines with responsibility for distribution to states. A variant on this proposal is to eliminate the "optional use" clause and require that manufacturers sell vaccine to states at the price negotiated by the CDC.

It is not clear a priori whether this would reduce the overall average cost to the public sector (Federal plus state governments). The weak evidence of a positive relationship between contract quantity and price noted above would suggest that this policy will tend to produce higher Federal contract prices. The recent experience in tying Veterans' Administration 
(VA) and Department of Defense (DOD) pharmaceutical discounts to Medicaid prices may also be instructive; in that case, prices paid by the VA and DOD increased (General Accounting office, 1991)..$^{13}$

\section{Public sector Production}

Public sector production is sometimes proposed as an alternative to the Federal role in purchasing vaccines. While it is sometimes argued that public production is needed to prevent dependence on foreign producers (see, for example, ortwein, 1987), the logic of this argument is loose. Privately-owned vaccine production facilities in the U.S. presumably offer as reliable a source of supply as would a public production facility, particularly since private facilities are so closely regulated. Even under "foreign" ownership, the force of public regulatory authority is undiminshed. ${ }^{14}$

The concerns about "fragility" of supply and "foreign dependence" seem to distill down to two types of risks. One is the risk that a private producer, whether foreign or domestically owned, may precipitously decide to cease production of a needed vaccine. The other is the risk that physical damage occurs to

${ }^{13}$ The GAO suggested, but did not specifically conclude from their study, that this increase was in fact caused by the OBRA Medicaid rebate provisions which tied Medicaid prices to VA and DOD prices.

${ }^{14}$ Furthermore, as Mowery and Mitchell (1993) note, the meaning of the distinction between "foreign" and "domestic" producers is becoming more and more clouded. 
the production facility. The latter risk is present whether ownership is public or private and can be diminshed only by stockpiling and by having multiple production facilities. (still more reduction in risk can be obtained by maintaining excess production capacity, though the cost of this policy would be quite substantial.) The risk of shut-down for business reasons can also be diminshed by stockpiling and by multiple sourcing (whether the sources be publicly or privately owned and operated).

One could also argue for public production as more efficient if costs of Federal purchases from private firms exceed the costs of public production. Cost advantages to public production, if they indeed exist, might be due to several factors. First, assuming that private firms can earn supra-competitive profits because of market imperfections, Federal procurement practices might not be succesful at extracting these supra-competitive profits.

Second, public organization of production may simply be more efficient. This second point certainly seems counter-intuitive in view of the administrative rigidities in public bureaucracies; indeed, the Biologic Products Advisory Committe of the state of Michigan, in its 1990 report, found the opposite to be true. In comparing the possibilities of moving from state-owned production to a private nonprofit institute subsidized by the state, they observed that

...a nonprofit institute... has advantages over a government 
setting for the operating flexibility for managing a function that is similar to a high tech manufacturing business producing a high quality product. Personnel and procurement decisions are easier to manage outside Departments of Civil Service and Management and Budget systems. (p.11)

One advantage of public production cited by this committee, which was quite important in their own deliberations, is immunity from liability. strictly speaking, this is not a pure efficiency saving, however, if adequate alternative means for insuring against adverse events are not in place.

\section{Health Care Reform and Vaccine Purchasing Arrangmonto}

Several aspects of proposed and/or likely changes in private health care financing arrangements may impact on the U.S. vaccine purchase and distribution system. First, inclusion of insurance coverage for vaccinations in a minimum Federally-mandated benefit package and expansion of health insurance coverage to persons currently lacking in coverage will substantially increase the role of private insurance as a financing mechanism. The impact of this change on vaccination rates may not be large however. Research on the price-elasticity of demand for vaccinations at the level of individuals and families suggests that the demand is not very price responsive (Frank et al., 1993). Thus, a lowering of the out-of-pocket money price due to increased insurance coverage may not by itself produce an increased demand for vaccinations. A related factor is the availability to many low income families of sources for free or low cost vaccinations (such as public health clinics). Moreover, aggregate vaccination rates do not appear sensitive to either the purchase mechanism 
nor the price structure in an area. Time prices, convenience and family structure all appear to exert more important influences on the demand for immunizations at the individual level (Frank, Dewa et al., 1993).

The foregoing also suggests that the effect of expanded insurance coverage may be greater if it is accompanied by increased provision of vaccines through private medical care providers. Recent experience suggests that private providers are increasingly referring patients to public clinics for vaccinations (Pearson, 1993). While this allows patients to obtain the vaccinations at lower costs, it also entails considerable additional time and inconvenience costs relative to the case where the vaccinations are provided in the course of regular medical or pediatric visits. Such time and inconvenience can be an important deterrent to obtaining vaccinations. According to this argument, the response of private medical providers (in terms of willingness to offer vaccination services) becomes a critical issue.

Health care reform is also expected to increase the market share of health maintenance organizations and other large provider groups. This will impact the supply of vaccination services if these types of providers are more likely to offer such services than private practitioners. We have not discovered evidence in the literature that this is in fact the case.

It is possible that health care reform will encourage group purchasing arrangements for providing vaccines or vaccination 
services which will reduce costs. Most conceptualizations of the statewide health insurance purchasing cooperatives (HIPCs) under health care reform characterize them as purchasing insurance rather than direct services or supplies such as vaccines. The health care plans themselves may purchase vaccines or vaccination services through group purchasing. Will health care reform encourage the emergence of large health care plans serving broad geographic areas that would be bulk purchasers of vaccines? Solid evidence on this point is lacking.

Finally, it is conceivable that the bureaucracy of health care reform will facilitate implementation of incentives to provide immunizations. For example, health insurers could be required to provide evidence of immunizations as a conditon for receiving payments from regional health alliances for enrolling children in their insurance plans. (If financial incentives are so effective for insurers, however, it is difficult to understand why cost-saving services such as immunizations have not been more aggressively promoted by insurers.)

VIII. Conclueions

In conclusion, our review of available evidence and data on purchasing options (both domestic and international) suggests that the current Federal approach to purchasing is in need of further scrutiny and possible change. It should be possible to modify procurement practices to encourage more firms to participate in the market. (Other strategies to encourage market entry suggested by other authors in this symposium will also be 
important in this regard.) It is hoped that this modification would also result in some further reduction in Federal contract prices but it must be admitted that the evidence linking increased numbers of sellers to lower prices is currently minimal. Our analysis of Federal procurement also raises the possibility that expansion of the Federal share of vaccine purchases through may raise Federal contract prices though it also would probably lower overall average prices.

Several major changes in Federal procurement policies were in fact implemented in 1994 (after the analysis for this paper was completed) with the Vaccines for Children Program, which was included in the 1993 Omnibus Budget Reconciliation Act (OBRA 1993). The scope of Federal purchasing was expanded as the Vaccines for Children Program unified purchasing under several different state and Federal programs into a single procurement process. As a result, it entailed substantial increases in the maximum quantity of doses to be purchased. (In some cases these increases were on the order of 50 per cent above the maximum quantity of the previous CDC contract.) Another important change in the procurement rules was the award of contracts to two bidders rather than one. The lowest price bidder receives approximately two-thirds of the total contract order and the second lowest bidder receives the remainder of the order.

The first round of procurements under the new program resulted in several multiple awards. The increase in quantity requirements was a major issue however, and in two procurements 
the CDC negotiated these requirements downward because the companies felt their ability to serve the private market would be drastically reduced. This concern is consistent with our discussion about the possibility of a positive relationship between purchase size and unit price.

Overall, we expect the consequences of the change in prices (resulting from OBRA 1993) for immunization rates to be quite small. Improvements in public immunization delivery systems and possible changes in private delivery systems under health care reform seem potentially much more important in achieving immunization targets. At current price levels, vaccine cost per se is probably not the critical factor inhibiting coverage. 


\section{REFERENCES}

Bikhchandani, Sushil and Chi-fu Huang, "The Economics of Treasury Securities Markets," Journal of Economic Perspectives $7(3): 117-134,1993$.

Biologic Products Advisory Committee, Dept. of Public Health, State of Michigan, Report to State Health Director, October 1990.

Burnett W.B., and Kovacic W.E., "Reform of United States Weapons Aqusition Policy: Competition, Teaming Agreements and

Dual-Sourcing" Yale Journal on Regulation 6 (2) 249-318 1989

Centers for Disease Control and Prevention, Vaccine Procurement Guidelines. Author, undated.

Frank, R.G., C.Dewa, E. Holt et al., "The Demand for Childhood Immunizations:Results from the baltimore Immunization study." Working Paper, Health Services Research and Development Center. The Johns Hopkins University, September 1993.

Friedman J., "A Non-cooperative Equilibrium for Supergames" Review of Economic Studies 38:1-12 1971

General Accounting office, Medicaid: Changes in Drug Prices Paid by VA and DOD Since Enactment of Rebate Provisions. September 1991.

Greer, Willis R. and Shu S. Liao, "An Analysis of Risk and Return in the Defense Market: Its Impact on Weapon System Competition," Management ScienceU 32(10):1259-1273, 1986.

Hansen, Robert, "Auctions with Endogenous Quantity," Rand Jounral of Economics, Spring 1988.

Institute of Medicine, The Childrens' Vaccine Initiative. Washington: National Academy of Science Press, 1993.

Johnston, Mark Andrew. Australia's Pharmaceutical Pricing Strategy. Ph.D. thesis in Public Policy, Harvard University, Cambrdige, Mass., January 1990.

Judge, R. et al. Econometrics 2nd Edition. New York: Wiley, 1991.

Luton, Richard and R. Preston McAfee, "Sequential Procurement Auctions," Journal of Public Economics 31(2):181-195, 1986.

McAfee, R. Preston and John MCMillan, "Auctions and Bidding," Journal of Economic Literature 25(2):699-738, 1987.

Principal-Agent Analysis," Rand Journal of Economics 
$17(3): 326-338,1986$

Milgrom, Paul, "Auctions and Bidding: A Primer," Journal of Economic Perspectives 3(3):3-22, 1989.

Mowery, David $C$. and Violaine Mitchell, "An Assessment of the Feasibility and Market Impact of Expanded Foreign-Firm Participation in the US Vaccine Market." Paper prepared for the National Vaccine Program office, U.S. Dep.t of Health and Human Services, 1993.

Ortwein, Robert, "Will We be Forced to Rely on Foreign Countr4ies for Our Childrens" Innoculations? A Decision Facing Michigan's Policy Makers." Unpublished paper distributed by the office of Senator William A. Sederburg, state of Michigan, January 1987.

Pauly, Mark V., "Market Power, Monopsony, and Health Insurance Markets," Journal of Health Economics $7(2): 111-128,1988$.

Pearson, Howard, "American Academy of Pediatrics Testimony Before the National Vaccine Advisory Committee," Feb. 24, 1993.

Riley, John G., "Expected Revenues from Open and Sealed Bid Auctions," Journal of Economic Perspectives 3(3):41-50, 1989.

Robinson M.S., "Collusion and the Choice of Auction" Rand Journal of Economics 16 (1) 141-146 1985

Seshadri, Sudhindra, Kalyan Chatterjee, and Gary L. Lilien, "Multiple Source Procurement Competitions," Marketing science $10(3): 246-263,1991$. 
TABLE 1

Licenses for Vaccine Production

\begin{tabular}{||c|c|c|c|}
\hline Year & DPT & MMR & OPV \\
\hline 1977 & 13 & 2 & 2 \\
\hline 1978 & 12 & 2 & 2 \\
\hline 1979 & 10 & 1 & 2 \\
\hline 1980 & 9 & 1 & 1 \\
\hline 1981 & 9 & 1 & 1 \\
\hline 1982 & 8 & 1 & 1 \\
\hline 1983 & 8 & 1 & 1 \\
\hline 1984 & 8 & 1 & 1 \\
\hline 1985 & 8 & 1 & 1 \\
\hline 1986 & 6 & 1 & 1 \\
\hline 1987 & 6 & 1 & 1 \\
\hline 1988 & 6 & 1 & 1 \\
\hline 1989 & 6 & 1 & 1 \\
\hline 1990 & 6 & 1 & 1 \\
\hline 1991 & 6 & 1 & 1 \\
\hline 1992 & 6 & 1 & 1 \\
\hline
\end{tabular}

Source: FDA - IOM (1993) 
TABLE 2

Number of Bidders for COC Contracts

\begin{tabular}{||l|l|l|l|l|l||}
\hline Year & DPT & MMR & OPV & HIB & TD \\
\hline 1985 & 1 & 1 & 1 & 1 & 4 \\
\hline 1986 & 1 & 1 & 1 & 2 & 3 \\
\hline 1987 & 2 & 1 & 1 & 2 & 3 \\
\hline 1988 & 2 & 1 & 1 & 2 & 3 \\
\hline 1989 & 2 & 1 & 1 & 2 & 4 \\
\hline 1990 & 2 & 1 & 1 & 2 & 4 \\
\hline 1991 & 2 & 1 & 1 & 2 & 4 \\
\hline 1992 & 2 & 1 & 1 & 2 & 3 \\
\hline
\end{tabular}

Source: $C D C$ 
TABLE 3

Real Goverment Prices for Vaccines Per Dose 1977 - 1992

\begin{tabular}{|l|l|l|l|}
\hline Year & DPT & MMR & OPV \\
\hline 1977 & $\$ 0.25^{\circ}$ & $\$ 3.99$ & $\$ 0.50$ \\
\hline 1978 & $0.23^{\circ}$ & 3.60 & 0.48 \\
\hline 1979 & $0.21^{\circ}$ & 3.61 & 0.45 \\
\hline 1980 & $0.19^{\circ}$ & 3.29 & 0.42 \\
\hline 1981 & $0.17^{\circ}$ & 3.43 & 0.44 \\
\hline 1982 & $0.16^{\circ}$ & 4.17 & 0.50 \\
\hline 1983 & 0.42 & 4.71 & 0.58 \\
\hline 1984 & 0.63 & 5.20 & 0.70 \\
\hline 1985 & 2.05 & 6.37 & 0.74 \\
\hline 1986 & 2.75 & 7.73 & 1.42 \\
\hline 1987 & 6.76 & 9.39 & 1.20 \\
\hline $1988^{\circ}$ & 7.15 & 13.68 & 1.15 \\
\hline 1989 & 6.42 & 13.05 & 1.55 \\
\hline 1990 & 5.29 & 11.25 & 1.47 \\
\hline 1991 & 4.59 & 11.26 & 1.47 \\
\hline 1992 & 4.47 & 10.94 & 1.49 \\
\hline
\end{tabular}

-Inflation adjusted using CPI all items index a state purchase price.

${ }^{\text {bPrices after }} 1987$ include excise taxes. 
TABLE 4

Variables Used in Analysis of DPT, MMR, OPV

1977 - 1992

\begin{tabular}{||l|l|}
\hline LNGP & Log of Real CDC Purchase Price \\
\hline LNCP & Log of Real Catalogue Price \\
\hline NLIC & Number of ACt ive Licenses for a Vaccine \\
\hline Liab & $\begin{array}{l}\text { Dumy equal to } 1 \text { in Years 1988-1992, o } \\
\text { otherwi se }\end{array}$ \\
\hline DPT & Dumm equal to 1 for DPT, O otherwise \\
\hline MMR & Dummy equal to 1 for MMR, O otherwise \\
\hline LNEXPO & $\begin{array}{l}\text { Log of expected doses } \\
\text { Add i i onal Var iables Used in 1985-1992 } \\
\text { DPT, MMR, OPV, HIB, and DT Analysis }\end{array}$ \\
\hline N Bidders & Number of firms bidding on a contract \\
\hline
\end{tabular}


TABLE 5

Regression Results for DPT, MMR, OPV

1977 - 1992

Dependent Variable LNGP

\begin{tabular}{|c|c|c|c|}
\hline Variable & Coefficient* & Coefficient & Coefficient \\
\hline \multirow[t]{2}{*}{ LNCP } & $0.709^{\circ}$ & $0.971^{\circ}$ & $0.976^{\circ}$ \\
\hline & $(0.109)$ & $(0.075)$ & $(0.082)$ \\
\hline \multirow[t]{2}{*}{ NLIC } & 0.141 & 0.041 & 0.066 \\
\hline & $(0.097)$ & 10.0481 & $(0.050)$ \\
\hline \multirow[t]{2}{*}{ LNEXPQ } & $0.218^{\circ}$ & - & - \\
\hline & $(0.071)$ & - & - \\
\hline \multirow[t]{2}{*}{ LIAB } & $0.287^{\prime}$ & $0.259^{\circ}$ & - \\
\hline & $(0.086)$ & $(0.097)$ & - \\
\hline \multirow[t]{2}{*}{ DPT } & 0.519 & $0.848^{\circ}$ & $0.687^{\circ}$ \\
\hline & $(0.529)$ & $(0.289)$ & $(0.300)$ \\
\hline \multirow[t]{2}{*}{ MMR } & $1.535^{\circ}$ & $0.941^{\circ}$ & $0.936^{\circ}$ \\
\hline & $(0.193)$ & $(0.122)$ & $(0.129)$ \\
\hline CONSTANT & -4.99 & -1.72 & -1.89 \\
\hline Time & - & - & $0.026^{\circ}$ \\
\hline$R^{2}$ & 0.97 & 0.97 & 0.97 \\
\hline $\mathbf{N}$ & 41 & 48 & 48 \\
\hline
\end{tabular}

* Standard error in parentheses.

'Significant $p<0.05$ 


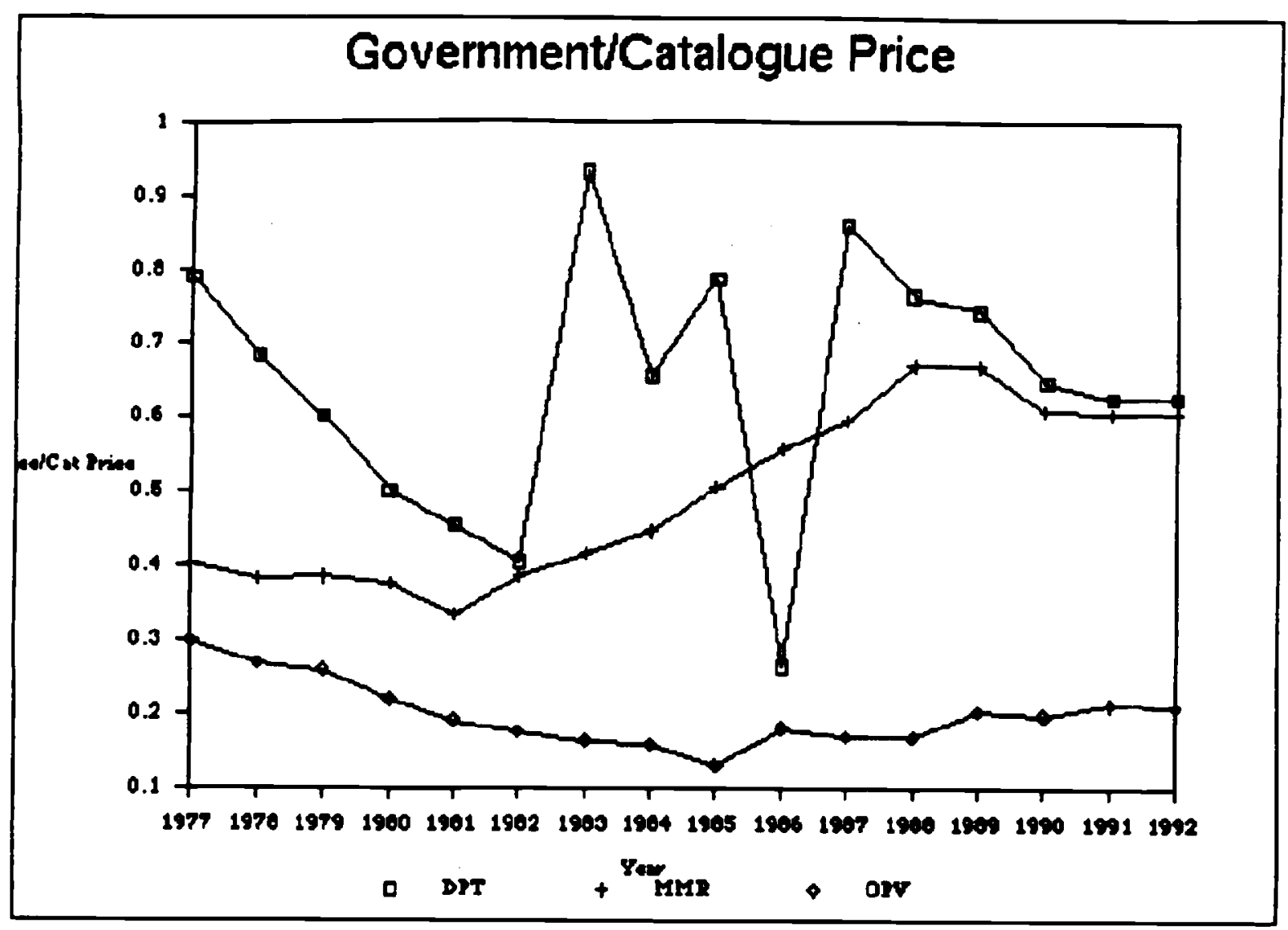

